\title{
Curcumin inhibits liver cancer by inhibiting DAMP molecule HSP70 and TLR4 signaling
}

\author{
BIQIONG REN ${ }^{1,2}$, SHUDI LUO ${ }^{2}$, XUEFEI TIAN ${ }^{1,2}$, ZHICHAO JIANG $^{1,2}$, GUOYING ZOU $^{1,2}$, \\ FEI XU ${ }^{1,2}$, TIEQIU YIN ${ }^{1,2}$, YIRAN HUANG ${ }^{2}$ and JUNLONG LIU ${ }^{2}$ \\ ${ }^{1}$ Clinical Laboratory of The Second People's Hospital of Hunan Province, ${ }^{2}$ Department of Clinical Laboratory Medicine, \\ Clinical Medical College, Hunan University of Chinese Medicine, Changsha, Hunan 410007, P.R. China
}

Received August 12, 2017; Accepted March 20, 2018

DOI: $10.3892 /$ or.2018.6485

\begin{abstract}
Curcumin has been revealed to inhibit liver cancer, however, no studies have reported that the mechanism of curcumin's action on liver cancer is related to damageassociated molecular pattern (DAMP) molecules heat shock protein 70 (HSP70) and the toll-like receptor 4 (TLR4) signaling. This study aimed to investigate whether the activation of TLR4 signaling by HSP70 could be inhibited by curcumin, thus investigating the possible mechanism of curcumin in the inhibition of liver cancer. Western blotting was used to evaluate the expression of the HSP70 and TLR4 in HepG2 cells and ELISA was used to detect the concentration of HSP70 in cell culture medium. A thermal tolerance HepG2 (HepG2TT) cell model was established to simulate HSP70 accumulation in the microenvironment. A certain concentration of curcumin was co-cultured with HepG2 and HepG2TT cells to observe the changes of HSP70 and TLR4. Our results revealed that heat stress significantly increased the expression of extracellular HSP70 (eHSP70) and TLR4 $(\mathrm{P}<0.01)$, but significantly reduced the expression of intracellular HSP70 $(\mathrm{P}<0.01)$. Curcumin inhibited proliferation, invasion, and metastasis of HepG2 cells, caused cells to remain in the DNA $\mathrm{S}$ phase, promoted apoptosis, and significantly reduced intracellular HSP70, eHSP70 and TLR4 levels of HepG2TT cells. Following the removal of curcumin, eHSP70 increased again. In summary, our results demonstrated that the antitumor
\end{abstract}

Correspondence to: Professor Biqiong Ren, Clinical Laboratory of The Second People's Hospital of Hunan Province, Hunan University of Chinese Medicine, 427 Furong Road, Changsha, Hunan 410007, P.R. China

E-mail: 13808481211@163.com

Abbreviations: DAMP, damage-associated molecular pattern; eHSP70, extracellular heat shock protein 70; TLR4, toll-like receptors 4; CCK-8, Cell Counting Kit-8; ELISA, enzyme-linked immunosorbent assay; IHC, immunohistochemistry; HepG2TT, thermal tolerance HepG2

Key words: liver cancer, HepG2, eHSP70, TLR4, curcumin effect of curcumin was related to the inhibition HSP70-TLR4 signaling.

\section{Introduction}

It has been widely reported that curcumin has anti-inflammatory, antimicrobial, antioxidant, antitumor, and even anti-neurodegenerative properties $(1,2)$. The underlying mechanism involved in the effect of curcumin is not understood especially in liver cancer inhibition. However, activation of the NF- $\mathrm{B}$ signaling pathway has often been associated with progression of liver cancer $(3,4)$, and HSP70 can activate $\mathrm{NF}-\kappa \mathrm{B}$ by binding to the TLR4 receptor (5). In addition, we revealed the anti-inflammatory effect of curcumin by decrease of plasma HSP70 levels in a rat model of thrombosis (unpublished data) therefore, we speculated that curcumin may have some interaction with HSP70.

The 'danger theory' $(6,7)$ of immunology suggests that DAMPs are associated with inflammation, autoimmune disease, cancer, and a variety of diseases associated with aging (8-10). Extracellular HSP70 is a typical DAMP (11), a pro-inflammatory molecule that causes the immune system of body to produce an immune response. Since many diseases associated with aging share a common origin and characteristics, such as genomic and epigenetic alterations, abnormal telomeres, inflammation and immune damage, a focus on DAMPs may reveal a new direction for disease research $(8,12)$.

In the present study, we demonstrated that curcumin inhibited proliferation, invasion, and metastasis of HepG2 cells, caused cells to remain in the DNA S phase, promoted apoptosis, and decreased the level of extracellular HSP70 and TLR4 of HepG2TT cells. Heat stress increases extracellular HSP70, which is used to study the change of the TLR4 pathway induced by it. Cell destruction, death or apoptosis can lead to the release of HSP70 from the intracellular to the extracellular space (13). The target of curcumin inhibition in liver cancer has not been clearly elucidated. This preliminary study revealed that curcumin could reduce extracellular HSP70 (DAMP molecule), and inhibit TLR4 signaling. Therefore, we deduced that the inhibition of liver cancer by curcumin was related to the inhibition of HSP70 and TLR4 signaling. 


\section{Materials and methods}

Cell culture and heat stress cell model establishment. HepG2 cells (a cell line originating from the liver cancer tissue of a 15 -year old white Caucasian male; is suitable for use in liver cancer cell metabolism although its histological type is derived from hepatoblastoma) (14) were obtained from the Central Laboratory of Xiangya School, Central South University (Changsha, China) and cultured in RPMI-1640 medium (Gibco; Thermo Fisher Scientific, Inc., Waltham, MA, USA) with $10 \%$ fetal bovine serum (FBS Premium; cat. no. P20-3302; PAN-Biotech GmbH, Aidenbach, Germany), $100 \mathrm{U} / \mathrm{ml}$ penicillin/streptomycin at $37^{\circ} \mathrm{C}$ in a humidified atmosphere containing $5 \% \mathrm{CO}_{2}$. Cells were grown in sterilized culture flasks and were passaged every two days with $0.25 \%$ trypsin (Gibco; Thermo Fisher Scientific, Inc.). For heat stress, the cells were heated in an incubator at $43^{\circ} \mathrm{C}$ for $80 \mathrm{~min}$, and named thermal tolerance HepG2 (HepG2TT) cells. Cells were treated with curcumin (Sigma-Aldrich, St. Louis, MO, USA) in complete medium, and the treatment concentrations of curcumin were 20 to $100 \mu \mathrm{M}$.

CCK-8 assay. HepG2 cells were seeded in 96-well plates (Corning, Inc., Corning, NY, USA) at a density of $5 \times 10^{4}$ cells $/ \mathrm{ml}$ in RPMI-1640 medium with 10\% FBS and $1 \%$ antibiotic-antimycotic solution and then incubated for $24 \mathrm{~h}$ at $37^{\circ} \mathrm{C}$ with $5 \% \mathrm{CO}_{2}$. HepG2 cells were treated with curcumin at concentrations of 20 to $100 \mu \mathrm{M}$. Following 24, 48 and $72 \mathrm{~h}$ of incubation, $10 \mu \mathrm{l}$ of CCK-8 (Dojindo Technologies, Inc., Kumamoto, Japan) was added to each well, and the cells were further incubated for $1 \mathrm{~h}$. The absorbance of each well was measured using a microplate reader (Addcare Bio-Tech Co., Ltd., Yantai, China) at a wavelength of $450 \mathrm{~nm}$. Cell proliferation was calculated according to the following equation: Survival percentage $(\%)=$ (absorption value of the treatment group)/(absorption value of the control group) $\mathrm{x} 100 \%$.

Wound-healing assay. Cells were plated in 6-well plates and grown overnight to confluence. Monolayers of cells were wounded by manual scraping with a $10-\mu 1$ pipette tip. Cells were rinsed with PBS and then treated with curcumin in serum-free medium at concentrations of 50 and $80 \mu \mathrm{M}$. Images were obtained at 0,24 and $48 \mathrm{~h}$ after wounding under an inverted microscope.

Transwell migration assay. Experiments were performed using a 24-well Transwell chamber (Corning Inc.). Briefly, $600 \mu \mathrm{l}$ of RMPI-1640 complete medium containing 10\% FBS was placed in the lower chamber. A total of 1x105 HepG2 cells in $100 \mu \mathrm{l}$ medium were seeded into the upper chamber (pore size, $8 \mu \mathrm{m}$ ). Then, HepG2 cells and medium were transferred into the chamber with curcumin (final concentrations of curcumin were 50 or $80 \mu \mathrm{M}$ ); untreated HepG2 cells were used as controls. The chamber was then incubated for $24 \mathrm{~h}$ at $37^{\circ} \mathrm{C}$ in a humidified atmosphere with $5 \% \mathrm{CO}_{2}$. The membrane was removed and its upper surface was wiped with a cotton swab to remove cells that had not migrated through the membrane. The membrane was then fixed in methyl alcohol for $20 \mathrm{~min}$ at room temperature and then stained with $0.1 \%$ crystal violet for $15 \mathrm{~min}$. The number of HepG2 cells that had migrated to the lower surface of the membrane were counted in 5 random high-power fields (HPFs) under an Olympus CKX41 light microscope.

Flow cytometric analysis of the cell cycle. The effect of curcumin on the cell cycle distribution was determined by flow cytometry. Briefly, HepG2 cells were seeded in culture bottles and treated with curcumin at 50 and $80 \mu \mathrm{M}$. Cells were harvested after $24 \mathrm{~h}$ and fixed at least $1 \mathrm{~h}$ with $70 \%$ ice-cold ethanol at $4^{\circ} \mathrm{C}$. Cells were washed with PBS and resuspended in $1 \mathrm{ml}$ of PBS, and then stained with propidium iodide PI). Cells were analyzed by flow cytometry using a FACSCalibur flow cytometer (Becton-Dickinson; BD Biosciences, CA, USA). The fraction of cells in the G0/G1, S and G2/M phases were analyzed using ModFit software, which was provided by the Third Hospital of Central South University.

Flow cytometric analysis of cell apoptosis. HepG2 cells were seeded in culture bottles and treated with curcumin at 50 and $80 \mu \mathrm{M}$. Cells were trypsinized (Gibco; Thermo Fisher Scientific, Inc.) and washed with PBS. The samples were centrifuged for $5 \mathrm{~min}$ at $2,000 \mathrm{xg}$ and the cells were harvested. The cells were resusupended in $500 \mu \mathrm{l}$ of binding buffer, then stained with Annexin V-FITC and PI. The number of apoptotic cells was detected and analyzed using flow cytometry.

Western blot analysis. Total proteins were extracted in lysis buffer and quantified using the BCA method. Proteins $(50 \mu \mathrm{g})$ were separated by SDS-PAGE ( 8 and 10\%). Proteins were then transferred to polyvinylidene fluoride (PVDF) membranes, and the membranes were incubated overnight at $4{ }^{\circ} \mathrm{C}$ with the following antibodies: SPAG9 (1:2,000; cat. no. ab12331; Abcam, Cambridge, MA, USA), HSP70 (1:2,000; cat. no. 10995-1-AP; Proteintech Group, Inc., Chicago, IL, USA), TLR4 (1:1,000; cat. no. 66350-1-Ig; Proteintech Group) and $\beta$-actin (1:4,000; cat. no. 60008-1-Ig; Proteintech Group). After incubation with goat anti-mouse/anti-rabbit IgG (1:4,000; cat. no. SA00001-1/ SA00001-15; Proteintech Group) at $37^{\circ} \mathrm{C}$ for $2 \mathrm{~h}$, bound proteins were visualized using superECL plus western blotting substrate (Pierce; Thermo Fisher Scientific, Inc.). Blots were exposed to a radiographic film.

ELISA assay. Levels of HSP70 were detected in the supernatant of HepG2 cells using the Human Heat Shock Protein 70 ELISA kit (Cusabio Technology, LLC, Wuhan, China) according to the manufacturer's instructions.

Statistical analyses. Statistical analyses were performed using SPSS 17.0 (SPSS, Inc., Chicago, IL, USA). Data are presented as the means \pm standard deviations. Statistical analyses were performed with two-way repeated measures ANOVA and two-way ANOVA. An LSD t-test was used in multiple comparison tests, and the statistical significance level was set at $\mathrm{P}<0.05$ (two-sided).

\section{Results}

Curcumin inhibits proliferation, migration, and invasion of HepG2 cells. In order to understand the effect of curcumin 
Table I. Curcumin inhibits proliferation of HepG2 cells in a concentration-dependent manner.

Cell proliferation rate $(\%)$

Concentration of curcumin

$24 \mathrm{~h}$

$48 \mathrm{~h}$

$72 \mathrm{~h}$

$20 \mu \mathrm{M}$
$50 \mu \mathrm{M}$
$80 \mu \mathrm{M}$
$100 \mu \mathrm{M}$
Two-way analysis of variance
Mauchly's test of sphericity
Main effect of curcumin
Main effect of time
Interaction

$93.43 \pm 3.77$

$53.26 \pm 2.57$

$45.86 \pm 1.76$

$39.61 \pm 0.37$

0.868

$\begin{array}{lc}\text { F, P } & 444.843,<0.001 \\ \text { F, P } & 97.455,<0.001 \\ \text { F, P } & 8.383,<0.001\end{array}$

Multiple comparisons between groups, LSD t-test
$20 \mu \mathrm{M}$ and $50 \mu \mathrm{M}$
$20 \mu \mathrm{M}$ and $80 \mu \mathrm{M}$
$20 \mu \mathrm{M}$ and $100 \mu \mathrm{M}$
$50 \mu \mathrm{M}$ and $80 \mu \mathrm{M}$
$50 \mu \mathrm{M}$ and $100 \mu \mathrm{M}$
$80 \mu \mathrm{M}$ and $100 \mu \mathrm{M}$

$\begin{array}{lrrr}\mathrm{P} & <0.001 & <0.001 & <0.001 \\ \mathrm{P} & <0.001 & <0.001 & <0.001 \\ \mathrm{P} & <0.001 & <0.001 & <0.001 \\ \mathrm{P} & 0.006 & 0.061 & 0.354 \\ \mathrm{P} & <0.001 & 0.010 & 0.001 \\ \mathrm{P} & 0.014 & 0.283 & 0.003\end{array}$

$\begin{array}{ll}82.44 \pm 6.58 & 84.17 \pm 5.93 \\ 48.24 \pm 3.14 & 28.34 \pm 1.80 \\ 40.95 \pm 2.85 & 24.62 \pm 6.86 \\ 37.10 \pm 2.39 & 8.730 \pm 0.55\end{array}$

$82.44 \pm 6.58$

$84.17 \pm 5.93$

$24.62 \pm 6.86$

0.55

The statistical significance level was set at $\mathrm{P}<0.05$. P, P-value; F, F-value.

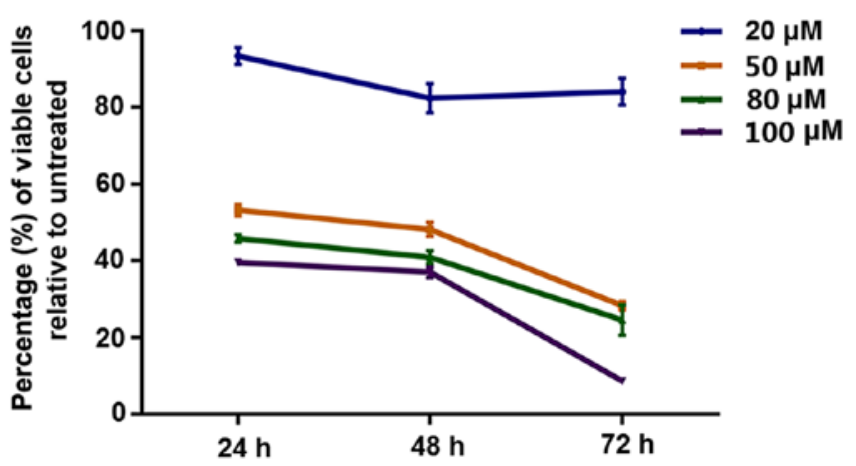

Figure 1. Curcumin inhibits proliferation. Curcumin affects the proliferation of HepG2 cells in a concentration-dependent manner. The proliferation rate at $20 \mu \mathrm{M}$ was significantly higher than the other three concentrations, and the higher the concentration, the stronger the inhibitory effect.

on cell proliferation, we performed a CCK-8 assay, which is a sensitive colorimetric assay using WST-8 dye to stain viable cells. The results revealed that curcumin inhibited the proliferation of HepG2 cells in a dose- and time-dependent manner $(\mathrm{F}=8.383$; $\mathrm{P}<0.001)$ (Fig. 1; Table I).

To investigate the effect of curcumin on cell migration and invasion, we performed an in vitro wound healing assay. As revealed in Fig. 2A and B, significantly fewer cells had migrated into the scratched area in the curcumin-treated cultures than in the untreated samples after $24 \mathrm{~h}$ of culture. To investigate whether heat stress, which increases extracellular HSP70 concentration, would affect the invasive abilities of HepG2 cells, we performed the wound healing assay with HepG2TT cells. As shown in Fig. 2C-E, the migration of cells that had been subjected to heat stress was significantly slower in the curcumin treated group than in the untreated group after 24 and $48 \mathrm{~h}$, but a concentration dependence was not evident. These results revealed that curcumin is an important inhibitor of migration and invasion in HepG2 and HepG2TT cells.

A Transwell migration assay also revealed that curcumin significantly inhibited the migration of HepG2 cells. There were significantly fewer cells per view in the samples treated with $80 \mu \mathrm{M}$ curcumin than in cells treated with $50 \mu \mathrm{M}$ curcumin (Fig. 3).

Curcumin halts the cell cycle in the $S$ phase and promotes apoptosis of HepG2 cells. Flow cytometry was used to analyze the effects of curcumin on the cell cycle and apoptosis. Compared with untreated HepG2 cells, the percentage of cells in the S phase of HepG2 cells treated with $80 \mu \mathrm{M}$ curcumin was significantly higher than in the untreated cells (Fig. 4A and B). The percentage of apoptosis in cells treated with both 50 and $80 \mu \mathrm{M}$ of curcumin was significantly higher than that in the untreated HepG2 cells (Fig. 5A and B).

Curcumin reduces the expression of HSP70 and TLR4. Western blot analyses revealed that HepG2 cells express both HSP70 and TLR4 and that curcumin treatment decreased the expression of HSP70 and TLR4. Heat stress also significantly reduced the expression of HSP70 and TLR4. Curcumin downregulates the expression of intracellular HSP70 in HepG2 cells, but has the opposite effect in HepG2TT cells. Curcumin downregulated the expression of TLR4 in HepG2 cells, but had no effect in HepG2TT cells (Fig. 6A and B). 
$\mathbf{A}$
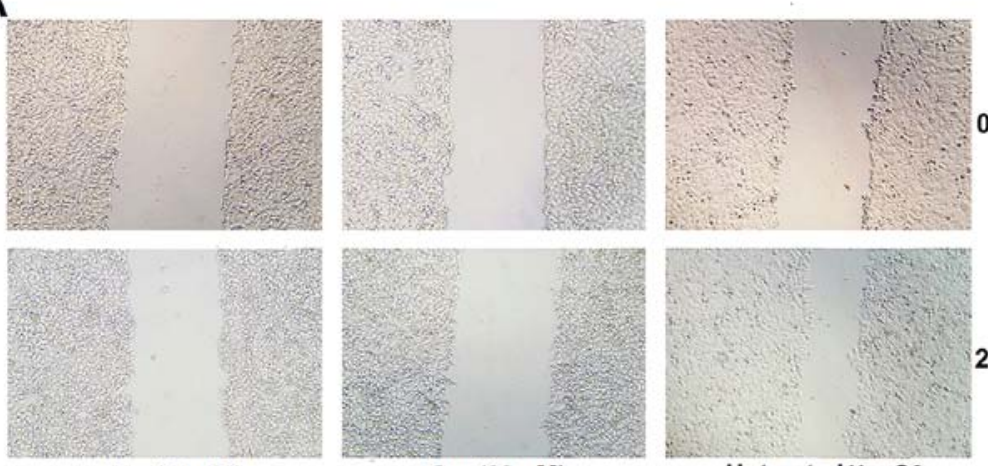

B

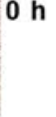

$24 \mathrm{~h}$

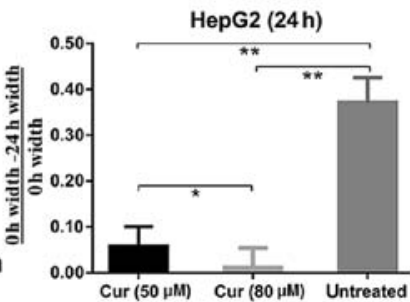

\section{C}
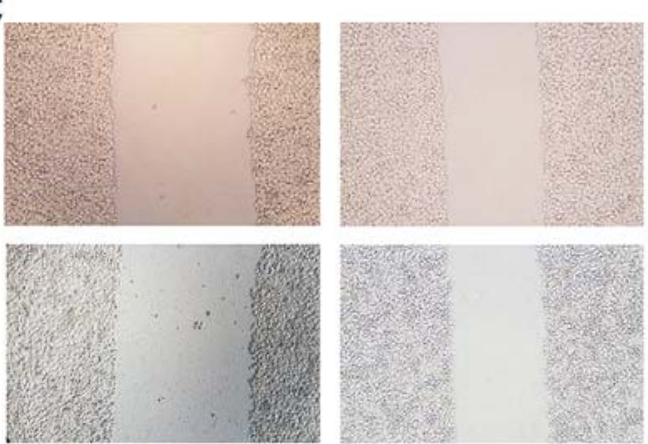

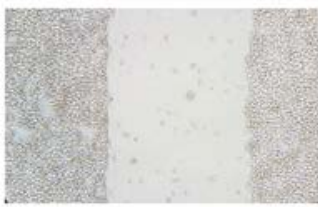

Cur $(50 \mu \mathrm{M})$

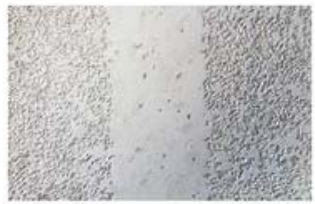

Cur $(80 \mu \mathrm{M})$
Untreated HepG2
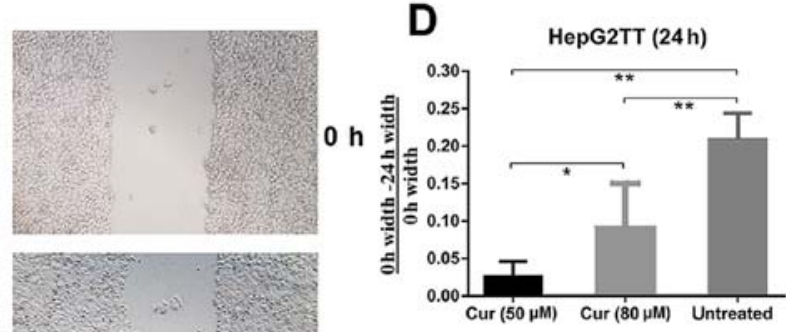

$24 \mathrm{~h}$

\section{E}

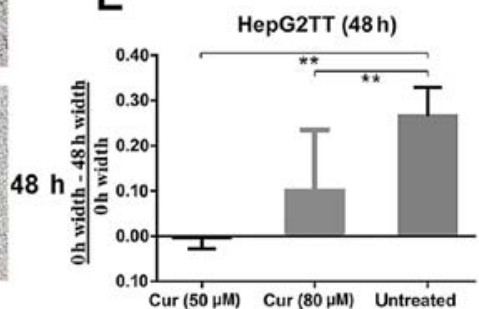

Figure 2. Curcumin inhibits migration in a wounding healing assay. (A) Representative images of plated HepG2 cells immediately and at $24 \mathrm{~h}$ after wounding. Cells were treated with 50 or $80 \mu \mathrm{M}$ curcumin or left untreated. (B) The width of the wound at 0 h in HepG2 cells minus the 24 -h scratch width vs. the 0 -h scratch width. (C) Representative images of plated heat-stressed HepG2 cells immediately and at 24 and 48 h after wounding. (D) The width of the wound at $0 \mathrm{~h}$ in HepG2TT cells minus the 24-h scratch width vs. the 0 -h scratch width. (E) The width of the wound at $0 \mathrm{~h}$ in HepG2TT cells minus the 48 -h scratch width vs. the 0 -h scratch width. HepG2TT cell migration was significantly slower in the curcumin-treated group than in the untreated group both after $24 \mathrm{~h}$ and 48 h. ${ }^{*} \mathrm{P}<0.01,{ }^{* *} \mathrm{P}<0.001$.

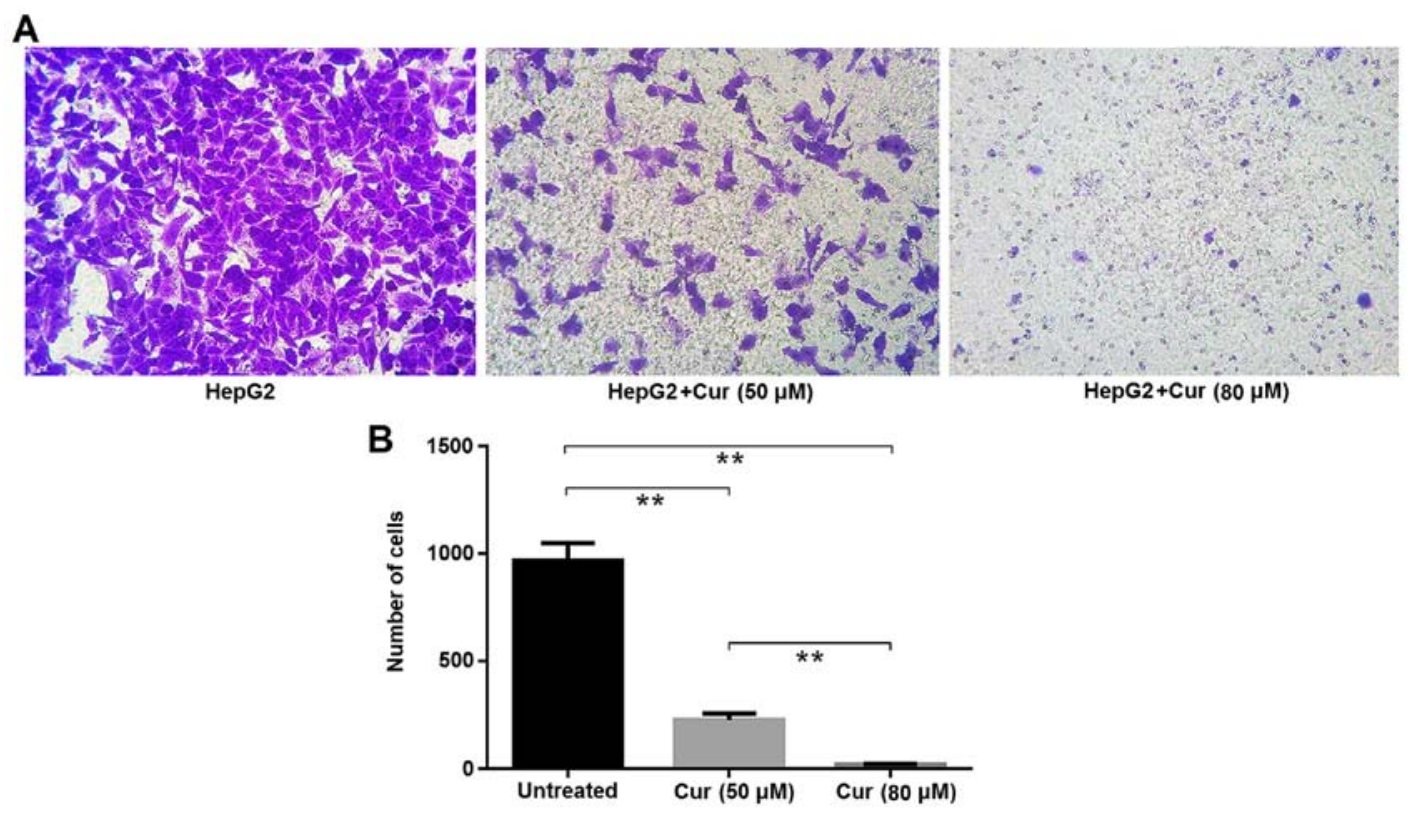

Figure 3. Curcumin inhibits migration in a Transwell migration assay. (A) Representative images of the membranes from the Transwell assays with untreated HepG 2 cells, HepG2 cells treated with $50 \mu \mathrm{M}$ curcumin, and HepG2 cells treated with $80 \mu \mathrm{M}$ curcumin. (B) Number of cells that migrated through the membrane per field of view $(967.6 \pm 81.71,226.6 \pm 30.14,19.2 \pm 3.22)$. ${ }^{* *} \mathrm{P}<0.001$. 

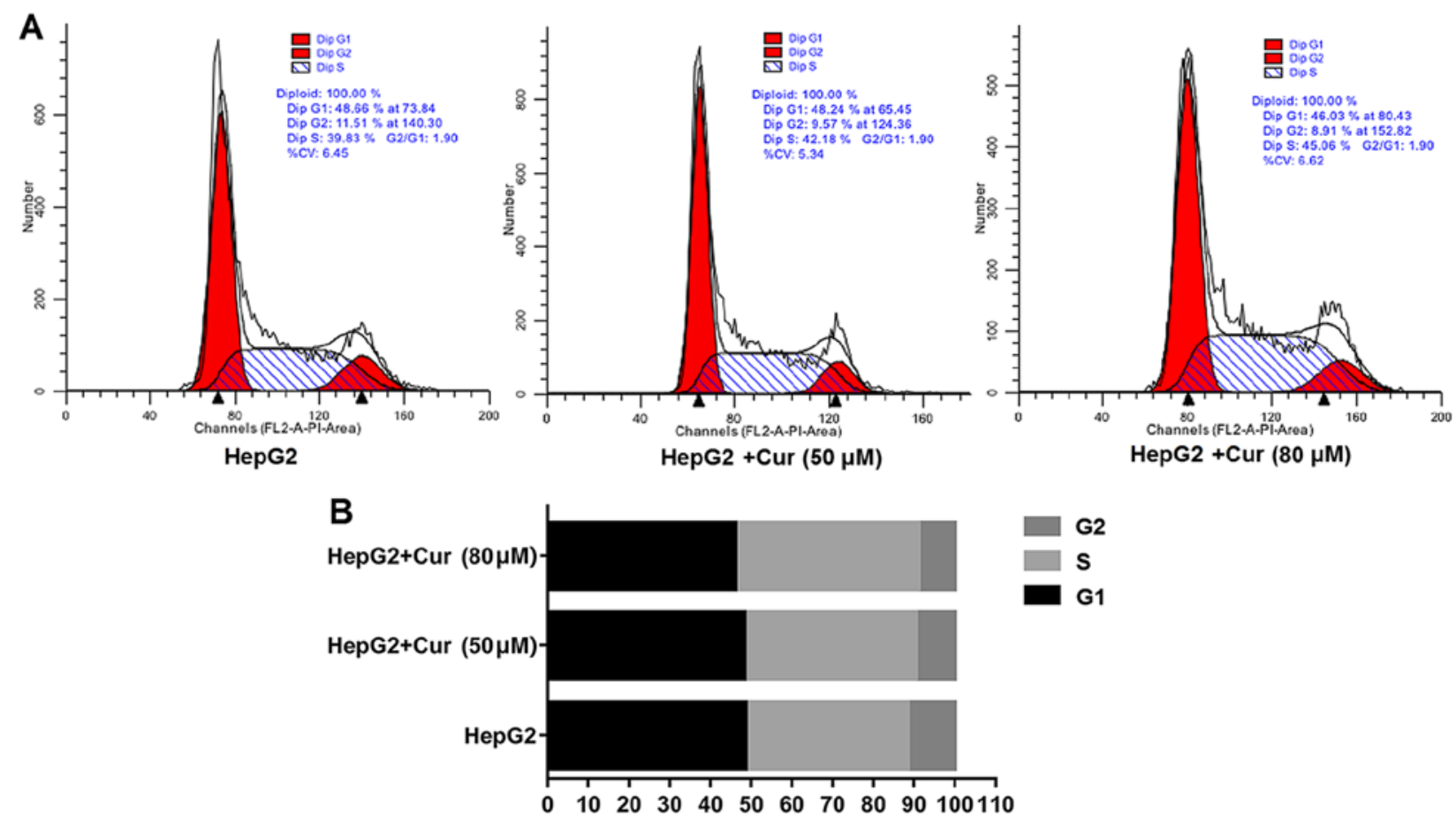

Figure 4. Curcumin halts the cell cycle in the S phase and promotes apoptosis. (A) Representative flow cytometric traces of untreated HepG2 cells (left) and cells treated with $50 \mu \mathrm{M}$ (middle) and $80 \mu \mathrm{M}$ (right) curcumin. The number of cells in the S phase of treated HepG2 cells with curcumin ( $80 \mu \mathrm{M}$ ) was higher than in untreated HepG2 cells. (B) The percentages of cells in the S phase.
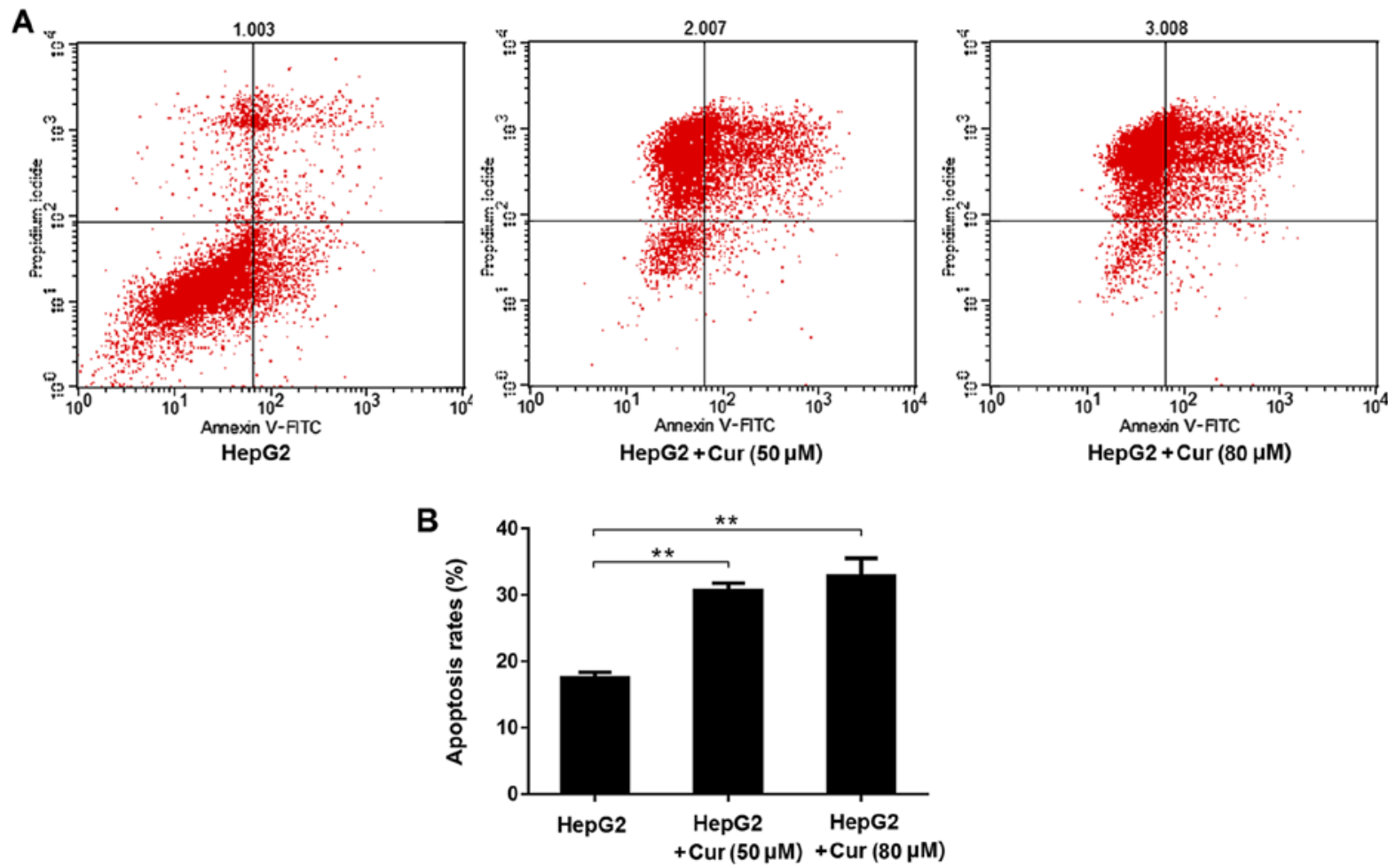

Figure 5. Curcumin promotes apoptosis. (A) Representative flow cytometric traces of untreated HepG2 cells (left) and cells treated with $50 \mu \mathrm{M}$ (middle) and $80 \mu \mathrm{M}$ (right) of curcumin stained with Annexin V-FITC and PI. (B) The percentage of apoptotic cells. ${ }^{* *} \mathrm{P}<0.001$.

Effects of curcumin on eHSP70 in HepG2TT cells. Compared with HepG2 cells, the concentration of eHSP70 was significantly increased in HepG2 cells subjected to heat stress. Curcumin treatment significantly decreased eHSP70 of HepG2TT cells; the changes of intracellular HSP70 were opposite to that of eHSP70, and the change of TLR4 expression was consistent with the change of eHSP70. After removing the effect of curcumin on HepG2TT cells, eHSP70 was recovered again (Fig. 7). 

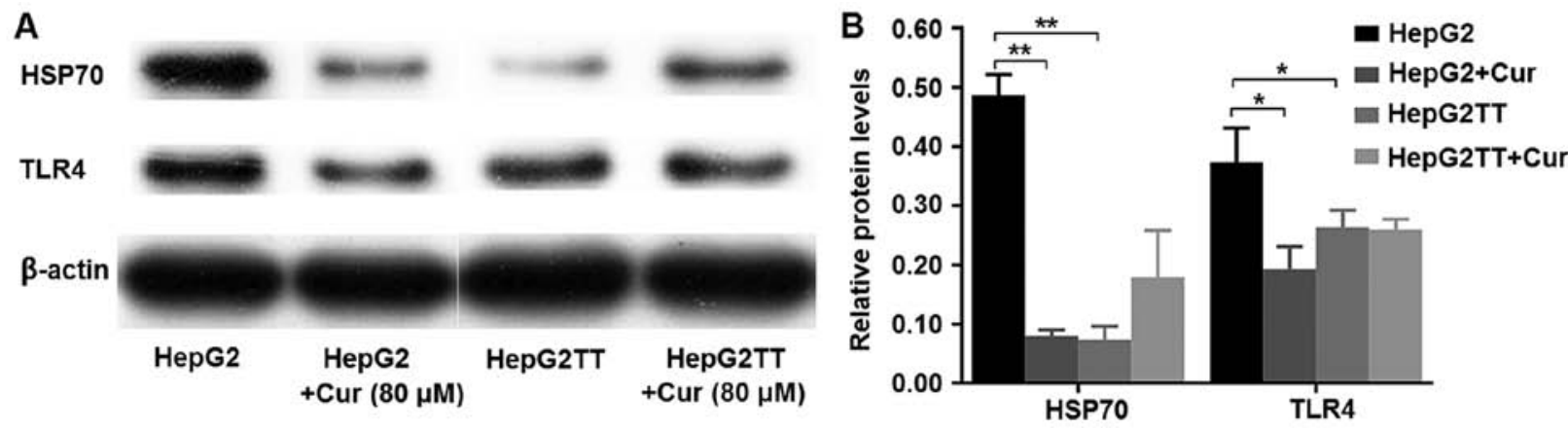

Figure 6. Curcumin downregulates the expression of intracellular HSP70 in HepG2 cells, but has the opposite effect in HepG2TT cells. Curcumin downregulated the expression of TLR4 in HepG2 cells, but had no effect in HepG2TT cells. (A and B) Western blotting and quantification of intracellular HSP70 and TLR4 in HepG2 and HepG2GTT cells, treated with or without curcumin. ${ }^{*} \mathrm{P}<0.01,{ }^{* * *} \mathrm{P}<0.001$.
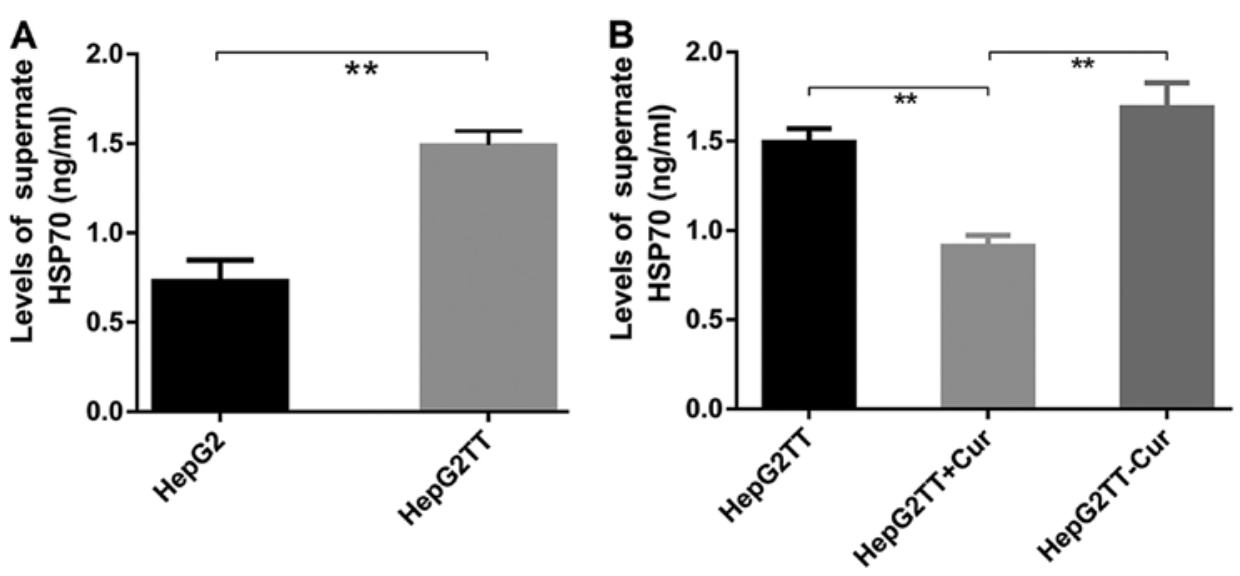

Figure 7. Curcumin downregulates the concentration of extracellular HSP70 in supernatants from HepG2TT cells. (A) Levels of extracellular HSP70 determined by ELISA. The concentration of extracellular HSP70 in supernatants from HepG2 and HepG2TT cells. (B) The concentration of extracellular HSP70 in supernatants from HepG2TT cells co-cultured with curcumin and following the removal of the effect of curcumin. ${ }^{* *} \mathrm{P}<0.001$.

\section{Discussion}

Curcumin is a polyphenol isolated from the traditional Chinese medicine turmeric rhizome which has a wide range of antitumor, anti-inflammatory, antioxidant, anti-atherosclerosis, and anti-depression activity $(1,2)$, however, the underlying mechanism of curcumin action is controversial $(15,16)$.

We used a CCK-8 assay, an in vitro wound healing assay and a Transwell migration assay and confirmed that treatment of HepG2 cells with curcumin significantly inhibited proliferation, invasion, and migration in a concentration-dependent manner. Flow cytometric results revealed that the cell cycle was blocked in the S phase in cells treated with curcumin, and apoptosis was increased, although there was no statistical significance. Further study is warranted to confirm the results.

According to research, tumor cells can release HSP70 into the extracellular environment, and high levels of HSP70 are detected in the peripheral blood of patients with various types of tumors $(17,18)$. High levels of HSP70 have also been detected in the sera of patients with cancer including those with liver cancer (18). We also detected a high expression of HSP70 and TLR4 in cancer tissues of patients with liver cancer. Our previous study revealed that the serum HSP70 levels in patients with hepatitis cirrhosis, as well as in patients with liver cancer, were higher than normal (19). These findings revealed that DAMP HSP70 is associated with the pathological process both of inflammation and cancer.

In this study, we found that HSP70 was excreted from HepG2 cells, TLR4 was expressed on the surface of HepG2 cells, and that heat stress increased the secretion of HSP70 into the HepG2 cell culture medium. As revealed in Fig. 6, in heat-stressed cells, the levels of intracellular HSP70 were decreased compared with non-stressed HepG2 cells, indicating that heat stress can release HSP70 from cells and significantly increase eHSP70 (as shown in Fig. 7). Co-culture with curcumin in HepG2 cells significantly decreased eHSP70, however eHSP70 increased again after the removal of the effect of curcumin. We also observed that the expression of TLR4 in the cells, exhibited a concentration-dependent relationship, indicating that the increased expression of TLR4 in HepG2 cells was associated with eHSP70.

Extracellular HSP70 is a typical DAMP (20), and, like cytokines, it stimulates the expression of TLR4 receptors on the surface of immune and tumor cells (21). When HSP70 engages TLR4, NF- $\mathrm{KB}$ is activated promoting the transcription of inflammatory genes including cytokines, chemokines, and growth factors. It has been previously reported that curcumin inhibits the transcription of NF- $\kappa B$ (22), and the NF- $\kappa B$ pathway plays important roles in the occurrence and development of tumors $(23,24)$. TLR4 is the receptor of eHSP70, 
therefore, inhibition of this interaction can indirectly inhibit $\mathrm{NF}-\kappa \mathrm{B}$ activation.

In summary, our results demonstrated that the HSP70mediated activation of TLR4 signaling could be inhibited by curcumin, and the antitumor effect of curcumin was related to the inhibition of HSP70-TLR4 signaling, thus we speculated that curcumin inhibits the expression of TLR4 on the tumor cell by decreasing the levels of eHSP70, thereby inhibiting the NF- $\kappa \mathrm{B}$ pathway initiated by TLR4 signaling. Our data provides a new research direction to reveal the anticancer liver mechanism of curcumin, supporting its further evaluation in liver cancer therapy, and the HSP70-TLR4 pathway may be a potential target for liver cancer therapy.

\section{Acknowledgements}

We would like to thank Min $\mathrm{Xu}$ and Weimin $\mathrm{Wu}$ for the collection of materials.

\section{Funding}

The present study was supported in part by the Hunan Administration of Traditional Chinese Medicine Key Fund (no. 201720).

\section{Availability of data and materials}

The datasets used during the present study are available from the corresponding author upon reasonable request.

\section{Authors' contributions}

BR contributed to the conception and design. SL, XT and ZJ drafted and revised the manuscript. SL, GZ and FX acquired, analyzed and interpreted the data. TY, YH and JL performed all the experiments. All authors read and approved the manuscript and agree to be accountable for all aspects of the research in ensuring that the accuracy or integrity of any part of the work are appropriately investigated and resolved.

\section{Ethics approval and consent to participate}

Not applicable.

\section{Patient consent for publication}

Not applicable.

\section{Competing interests}

The authors declare that they have no competing interests.

\section{References}

1. Egan ME, Pearson M, Weiner SA, Rajendran V, Rubin D, Glöckner-Pagel J, Canny S, Du K, Lukacs GL and Caplan MJ: Curcumin, a major constituent of turmeric, corrects cystic fibrosis defects. Science 304: 600-602, 2004.

2. Zeitlin P: Can curcumin cure cystic fibrosis? N Engl J Med 351: 606-608, 2004.
3. Karin M: Nuclear factor-kappaB in cancer development and progression. Nature 441: 431-436, 2006.

4. Pikarsky E, Porat RM, Stein I, Abramovitch R, Amit S, Kasem S, Gutkovich-Pyest E, Urieli-Shoval S, Galun E and Ben-Neriah Y: NF-kappaB functions as a tumour promoter in inflammationassociated cancer. Nature 431: 461-466, 2004.

5. Wheeler DS, Chase MA, Senft AP, Poynter SE, Wong HR and Page K: Extracellular Hsp72, an endogenous DAMP, is released by virally infected airway epithelial cells and activates neutrophils via Toll-like receptor (TLR)-4. Respir Res 10: 31, 2009.

6. Polly Matzinger P: Tolerance, danger, and the extended family. Annu Rev lmmunol 12: 991-1045, 1994.

7. Huang J, Xie Y, Sun X, Zeh HJ III, Kang R, Lotze MT and Tang D: DAMPs, ageing, and cancer: The 'DAMP Hypothesis'. Ageing Res Rev 24A: 3-16, 2015.

8. Nefla M, Holzinger D, Berenbaum F and Jacques C: The danger from within: Alarmins in arthritis. Nat Rev Rheumatol 12: 669-683, 2016.

9. Pécheur EI: Curcumin against hepatitis $C$ virus infection: Spicing up antiviral therapies with 'nutraceuticals'? Gut 63: 1035-1037, 2014.

10. Adewoye AH and McMahon L: Chaperones and disease. N Engl J Med 353: 2821-2822, author reply 2821-2822, 2005.

11. Land WG: Role of heat shock protein 70 in innate alloimmunity. Front Immunol 2: 89, 2012.

12. Li G, Tang D and Lotze MT: Ménage à Trois in stress: DAMPs, redox and autophagy. Semin Cancer Biol 23: 380-390, 2013.

13. Brusa D, Migliore E, Garetto S, Simone M and Matera L: Immunogenicity of $56^{\circ} \mathrm{C}$ and UVC-treated prostate cancer is associated with release of HSP70 and HMGB1 from necrotic cells. Prostate 69: 1343-1352, 2009.

14. López-Terrada D, Cheung SW, Finegold MJ and Knowles BB: Hep G2 is a hepatoblastoma-derived cell line. Hum Pathol 40: 1512-1515, 2009.

15. Baker M: Deceptive curcumin offers cautionary tale for chemists. Nature 541: 144-145, 2017.

16. Heger M: Drug screening: Don't discount all curcumin trial data. Nature 543: 40, 2017.

17. Rozenberg P, Kocsis J, Saar M, Prohászka Z, Füst G and Fishelson Z: Elevated levels of mitochondrial mortalin and cytosolic HSP70 in blood as risk factors in patients with colorectal cancer. Int J Cancer 133: 514-518, 2013.

18. Gehrmann M, Cervello M, Montalto G, Cappello F, Gulino A, Knape C, Specht HM and Multhoff G: Heat shock protein 70 serum levels differ significantly in patients with chronic hepatitis, liver cirrhosis, and hepatocellular carcinoma. Front Immunol 5: 307, 2014

19. Ren B, Luo S, Xu F, Zou G, Xu G, He J, Huang Y, Zhu H and $\mathrm{Li}$ Y: The expression of DAMP proteins HSP70 and cancer-testis antigen SPAG9 in peripheral blood of patients with HCC and lung cancer. Cell Stress Chaperones 22: 237-244, 2017.

20. Timmermans K, Kox M, Vaneker M, van den Berg M, John A van Laarhoven A, van der Hoeven $\mathrm{H}$, Scheffer GJ and Pickkers P: Plasma levels of danger-associated molecular patterns are associated with immune suppression in trauma patients. Intensive Care Med 42: 551-561, 2016.

21. Camp SM, Ceco E, Evenoski CL, Danilov SM, Zhou T, Chiang ET, Moreno-Vinasco L, Mapes B, Zhao J, Gursoy G, et al: Unique toll-like receptor 4 activation by NAMPT/PBEF induces NFKB signaling and inflammatory lung injury. Sci Rep 5: $13135,2015$.

22. Marquardt JU, Gomez-Quiroz L, Arreguin Camacho LO, Pinna F, Lee YH, Kitade M, Domínguez MP, Castven D, Breuhahn K, Conner EA, et al: Curcumin effectively inhibits oncogenic $\mathrm{NF}-\mathrm{\kappa B}$ signaling and restrains stemness features in liver cancer. J Hepatol 63: 661-669, 2015.

23. Liang Y, Zheng T, Song R, Wang J, Yin D, Wang L, Liu H, Tian L, Fang X, Meng X, et al: Hypoxia-mediated sorafenib resistance can be overcome by EF24 through Von Hippel-Lindau tumor suppressor-dependent HIF-1 $\alpha$ inhibition in hepatocellular carcinoma. Hepatology 57: 1847-1857, 2013.

24. Lim SO, Li CW, Xia W, Cha JH, Chan LC, Wu Y, Chang SS, Lin WC, Hsu JM, Hsu YH, et al: Deubiquitination and Stabilization of PD-L1 by CSN5. Cancer Cell 30: 925-939, 2016. 